\title{
A comparative study of the clinical characteristics and outcomes of HR-positive HER2-negative breast cancer patients over and under 65 years old
}

\author{
Chang Shin Jung', Youn Joo Jung', Dong II Kim', Seungju Lee', Seok Kyung Kang', Su Bong Nam², Hyun Yul Kim \\ ${ }^{1}$ Department of Surgery, Pusan National University Yangsan Hospital, Yangsan; \\ ${ }^{2}$ Department of Plastic and Reconstructive Surgery, Pusan National University School of Medicine, Yangsan, Korea
}

Purpose: The purpose of this study was to compare the clinical characteristics and outcomes of hormone receptor-positive (HR+) human epidermal growth factor 2-negative (HER2-) breast cancer among elderly patients (over 65 years old) and younger patients.

Methods: This was a retrospective cohort study of 328 patients who were treated for breast cancer at Pusan National University Yangsan Hospital between January 2009 and December 2014. Tumor characteristics, surgical methods, and survival outcomes were compared between the two age groups ( $<65$ and $\geq 65$ years old). Kaplan-Meier curves for disease-free survival (DFS) and overall survival (OS) were also constructed according to the age groups.

Results: Among the 328 patients with HR+ HER2- breast cancer, 184 (56.1\%) were < 65 years old and $144(43.9 \%)$ were $\geq 65$ years old. Breast cancer stages were similar between the two age groups, but the older patients were treated less often with chemotherapy ( $81 \%$ vs. $66 \%, P=0.002$ ). During the follow-up period, 17 deaths and 36 cases of recurrence or metastasis were reported. There was no difference in DFS between the two groups $(P=0.840)$; however, the $O S$ of the older age group was significantly lower than that of the younger age group $(\mathrm{P}=0.015)$.

Conclusion: This study suggested that HR+ HER2- breast cancer patients belonging to the two age groups had no significant difference in DFS. However, older age is an independent factor affecting OS rate. Therefore, even if patients are old, but their physical condition is satisfactory, standard and active treatment may be necessary, similar to that given to younger patients.

Keywords: Aged, Breast neoplasm, Receptor, ErbB-2

\section{INTRODUCTION}

In Korea, breast cancer rates are increasing, whereas the rates of

Received: Mar 18, 2021 Revised: May 21, 2021 Accepted: May 31, 2021 Correspondence to: Hyun Yul Kim

Department of Surgery, Pusan National University Yangsan Hospital, 20 Geumo-ro, Mulgeum-eup, Yangsan 50612, Korea

Tel: +82-51-240-7389, Fax: +82-51-240-7442

E-mail: isepa102@naver.com

ORCID: Chang Shin Jung (https://orcid.org/0000-0002-2945-4191), Youn Joo Jung (http://orcid.org/0000-0002-9647-8556), Dong II Kim (https://orcid.org/00000001-9874-1322), Seungju Lee (https://orcid.org/0000-0001-5100-0017), Seok Kyung Kang (https://orcid.org/0000-0002-4119-9445), Su Bong Nam (http://orcid. org/0000-0002-9661-0879), Hyun Yul Kim (https://orcid.org/0000-0001-77177734)

Copyright (C) 2021 Korean Society of Surgical Oncology

This is an Open Access article distributed under the terms of the Creative Commons Attribution Non-Commercial License (http://creativecommons.org/licenses/by-nc/4.0) which permits unrestricted non-commercial use, distribution, and reproduction in any medium, provided the original work is properly cited. other cancers are decreasing annually [1]. In general, Korean women in their forties have a high breast cancer incidence rate, unlike the rate in Western countries [1,2]. However, despite the country having an aging society, with the proportion of those aged 65 and older increasing, studies on elderly breast cancer patients remain insufficient.

Elderly patients have often been excluded from clinical trials, and prospective studies are usually inadequate, making it difficult to establish an appropriate treatment [3,4]. In addition, compared with younger patients, elderly patients are more unlikely to receive active treatments such as breast-conserving surgery, endocrine therapy, radiotherapy, or chemotherapy [5].

Breast cancer in elderly patients is frequently of the luminal type, with a less aggressive pathology [6,7]. In this study, we compared the clinical characteristics, prognostic factors, and long-term outcomes of hormone receptor-positive (HR+), human epidermal growth factor receptor 2-negative (HER2-) breast cancer among elderly patients (over 65 years old) and younger patients. 


\section{METHODS}

\section{Study population}

In this retrospective study, we analyzed the data of 328 patients who were treated for invasive breast cancer between January 2009 and December 2014 at Pusan National University Yangsan Hospital and Pusan National University Hospital. The patients were divided into two age groups: $<65$ and $\geq 65$ years old.

We classified a total of 328 patients with estrogen receptor-positive or progesterone receptor-positive HER2- breast cancer as having luminal type A breast cancer. Immunohistochemistry (IHC) staining permits the detection and localization of estrogen receptor/progesterone receptor within sections from formalin-fixed, paraffin-embedded tissues. Staining of $>20 \%$ of tumor cell nuclei is considered positive. Staining of 5\% to $19 \%$ of tumor cell nuclei is considered borderline. Staining of $<5 \%$ of tumor cell nuclei is considered negative. HER2 proteins, our study considers IHC result of 0 to $1+$ as negative and $3+$ as positive. A Her2/neu result of $2+$ is considered a negative result unless verified by silver in-situ hybridization.

The basic clinical characteristics of the patients were obtained using electronic medical records. We analyzed the clinicopathologic factors affecting prognosis in both age groups. The data included age at diagnosis, body mass index $\left(\mathrm{BMI} ; \mathrm{kg} / \mathrm{m}^{2}\right)$, T stage, $\mathrm{N}$ stage, histologic grade, Ki-67 status, and the type of surgery, chemotherapy, radiotherapy, and endocrine therapy. The breast cancer stage was classified using the 7 th edition of the American Joint Committee on Cancer guidelines. The Ki-67 cutoff value was set at $15 \%$. For detection of local and distant recurrence, clinical follow-up was performed every 3-6 months for the first 5 years after primary therapy.

This study was approved by the Institutional Review Board of the Pusan National University Yangsan Hospital (IRB No. 052021-023). Informed consent was not required for this study.

\section{Statistical methods}

Overall survival (OS) was defined as the time from the date of $\mathrm{cu}^{-}$ rative surgery to the date of death or last follow-up, whereas disease-free survival (DFS) was measured from the date of curative surgery to the date of local recurrence or distant metastasis. Fiveyear DFS and OS curves of the two age groups were calculated using the Kaplan-Meier method and were compared using the logrank rest. Statistical analyses were performed using SPSS version 23.0 (IBM Corp., Armonk, NY, USA).

\section{RESULTS}

The median ages of the younger and older groups were 49 years (range, 25-64 years) and 70 years (range, 65-87 years), respectively. The proportion of patients with a high BMI was higher in the older group than that in the younger group $(\mathrm{P}<0.001)$ (Table 1$)$. Distribution of pathologic tumor stage was different in the two groups $(\mathrm{P}=0.041)$ (Table 1$)$. However, there was no statistically significant difference in the TNM final stage between the two groups. As expected, the incidence of comorbidity was greater among the older age group than younger age group $(\mathrm{P}<0.001)$ (Table 1).

Receiving hormone therapy was not different in both groups, but there were significant differences between the two groups in terms of surgical method $(\mathrm{P}<0.001)$, chemotherapy $(\mathrm{P}=0.002)$, and radiation therapy $(\mathrm{P}<0.001)$ (Table 2$)$.

The majority of patients in the younger age group (81.5\%) underwent breast-conserving surgery but older patients did not $(40.3 \%)(\mathrm{P}<0.001)$.

In terms of treatment, for the younger age group, $81.0 \%, 89.1 \%$, and $98.8 \%$ of patients received chemotherapy $(\mathrm{P}=0.002)$, radiotherapy $(\mathrm{P}<0.001)$, and hormone therapy $(\mathrm{P}=0.257)$ respectively, whereas the older patients were less likely to have received chemotherapy or radiotherapy.

During the follow-up period, 17 deaths and 36 cases of recurrence or metastasis were reported in both groups (Table 3).

In the younger group, 20 of 184 patients (10.8\%) had recurrence or metastasis. Local recurrences were observed in 10 of $184 \mathrm{pa}-$ tients (5.4\%): six in the remnant breast, one in the chest wall, two in the axillary lymph, and one in multiple recurrences (remnant breast and axillary lymph). Metastasis occurred in 10 of 184 patients (5.4\%): two in the lung, one in the bones, one in the liver, four in the brain, and two in multiple metastases (lung and bone).

In the older age group, the rate of locoregional recurrence or metastasis was not significantly different when compared to that of the younger group. Sixteen of 144 patients (11.1\%) had recurrence or metastasis. Local recurrences were observed in five of $144 \mathrm{pa}$ tients (3.4\%), all in axillary lymph nodes. Metastasis occurred in 11 of 144 patients (7.6\%): three in the lung, four in the bones, three in the liver, and one in multiple metastases (lung and bone).

The total number of deaths was 17 , five of 184 patients (2.7\%) in the younger age group and 12 of 144 patients (8.3\%) in the older age group. There were 10 deaths from metastasis, two of five patients (40\%) in the younger group and eight of 10 patients (66.7\%) in the elderly. Two of older patients and one of younger patients were deaths from other cancer.

Univariate and multivariate analyses were performed to identify 
Table 1. Characteristics of patients with estrogen receptor-positive breast cancer according to age

\begin{tabular}{|c|c|c|c|c|}
\hline Variable & Overall $(n=328)$ & Age $<65$ years $(n=184)$ & Age $\geq 65$ years $(n=144)$ & P-value \\
\hline $\mathrm{BMI}\left(\mathrm{kg} / \mathrm{m}^{2}\right)$ & & & & $<0.001$ \\
\hline Underweight (<18.5) & $6(1.8)$ & $3(1.6)$ & $3(2.1)$ & \\
\hline Normal weight $(18.5$ to $<23)$ & $112(33.9)$ & $80(43.5)$ & $32(22.2)$ & \\
\hline Overweight (23 to <25) & $79(24.1)$ & $45(24.5)$ & $34(23.6)$ & \\
\hline Obesity $(25$ to $<30)$ & $105(32.0)$ & $45(24.5)$ & $60(41.7)$ & \\
\hline Severe obesity (>34) & $26(7.9)$ & $11(6.0)$ & $15(10.4)$ & \\
\hline рT & & & & 0.041 \\
\hline 1 & $166(51.0)$ & $95(51.6)$ & $71(49.3)$ & \\
\hline 2 & $130(40.0)$ & $73(39.7)$ & $57(39.6)$ & \\
\hline 3 & $23(7.0)$ & $15(8.2)$ & 8 (5.6) & \\
\hline 4 & $9(3.0)$ & $1(0.5)$ & $8(5.6)$ & \\
\hline $\mathrm{pN}$ & & & & 0.971 \\
\hline 0 & $192(58.5)$ & $106(57.6)$ & $86(59.7)$ & \\
\hline 1 & $90(27.4)$ & $51(27.7)$ & $39(27.1)$ & \\
\hline 2 & $28(8.5)$ & $16(8.7)$ & $12(8.3)$ & \\
\hline 3 & $18(5.5)$ & $11(6.0)$ & $7(4.9)$ & \\
\hline Stage & & & & 0.520 \\
\hline 1 & $136(41.5)$ & $81(44.0)$ & $55(38.2)$ & \\
\hline$\|$ & $137(41.7)$ & 72 (39.1) & 65 (45.1) & \\
\hline III & 55 (16.8) & 31 (16.8) & 24 (16.7) & \\
\hline Tumor grade & & & & 0.560 \\
\hline 1 & 110 (33.5) & 66 (35.9) & 44 (30.6) & \\
\hline 2 & 164 (50.0) & 90 (48.9) & 74 (51.4) & \\
\hline 3 & 54 (16.5) & 28 (15.2) & $26(18.1)$ & \\
\hline $\mathrm{KI}-67$ & & & & 0.340 \\
\hline$<15 \%$ & $221(67.4)$ & 128 (69.3) & 93 (64.6) & \\
\hline$\geq 15 \%$ & 107 (32.6) & 56 (30.4) & $51(35.4)$ & \\
\hline \multicolumn{5}{|l|}{ Comorbidity } \\
\hline HTN & & & & $<0.001$ \\
\hline Yes & 117 (35.7) & 29 (15.8) & 88 (61.1) & \\
\hline No & $211(64.3)$ & 155 (84.2) & 56 (38.9) & \\
\hline DM & & & & $<0.001$ \\
\hline Yes & 50 (15.3) & $12(6.5)$ & 38 (26.4) & \\
\hline No & $278(84.7)$ & 172 (93.5) & 106 (73.6) & \\
\hline
\end{tabular}

Values are presented as number (\%).

BMI, body mass index; HTN, hypertension; DM, diabetes mellitus.

the prognostic factors for OS and DFS. The significant factors included age, BMI, type of surgery, tumor size, hormone therapy and Ki-67 in univariate analyses for OS. Multivariate analysis revealed that age, tumor size, hormone therapy and Ki-67 were significant factors for OS (Table 4). Table 5 shows that tumor size, node stage, TMN stage, nuclear grade, and Ki-67 were the significant factors for DFS in univariate analyses. Only tumor size was the significant factor for DFS in multivariate analyses. In multivariate analyses, tumor size had influence on OS and DFS.

The 5 -year OS and DFS rates in the younger age group $(n=184)$ were $97.8 \%$ and $92.6 \%$, respectively, whereas in the older age group, were $90.6 \%$ and $91.3 \%$, respectively, with a median follow-up peri- od of 64 months. Figs. 1 and 2 shows the OS and DFS Kaplan-Meier curves according to the age groups. No difference in DFS $(\mathrm{P}=$ 0.840 ) was observed between the two age groups (Fig. 1); however, the OS in the older age group was significantly lower than in the younger age group $(\mathrm{P}=0.015)$ (Fig. 2).

\section{DISCUSSION}

Almost 50\% of women diagnosed with breast cancer in the United States are $\geq 65$ years old, and the median age of diagnosis is 61 years $[8,9]$. Due to the growing population of people aged over 65 years owing to Korea's increasing life expectancy, the number of 
elderly breast cancer patients is also increasing.

We investigated the differences in OS and DFS between older and younger patients with HR+ HER2- breast cancer, which is the most frequent subtype, and its incidence is increasing compared to

Table 2. Treatment of patients with estrogen receptor-positive breast cancer according to age

\begin{tabular}{lcccc}
\hline Variable & $\begin{array}{c}\text { Overall } \\
(n=328)\end{array}$ & $\begin{array}{c}\text { Age }<65 \\
\text { years } \\
(n=184)\end{array}$ & $\begin{array}{c}\text { Age } \geq 65 \\
\text { years } \\
(n=144)\end{array}$ & P-value \\
\hline $\begin{array}{l}\text { Surgery } \\
\text { Breast conservation }\end{array}$ & $208(63.4)$ & $150(81.5)$ & $58(40.3)$ & $<0.001$ \\
$\quad$ Mastectomy & $120(36.6)$ & $34(18.5)$ & $86(59.7)$ & \\
$\begin{array}{l}\text { Chemotherapy } \\
\text { Adjuvant }\end{array}$ & $244(74.3)$ & $149(81.0)$ & $95(66.0)$ & \\
$\quad$ No chemotherapy & $84(25.7)$ & $35(19.0)$ & $49(34.0)$ & \\
Radiotherapy & & & & $<0.001$ \\
$\quad$ Yes & $235(71.6)$ & $164(89.1)$ & $71(49.3)$ & \\
$\quad$ No & $93(28.4)$ & $20(10.9)$ & $73(50.7)$ & \\
Hormone therapy & & & & 0.257 \\
$\quad$ Yes & $322(98.2)$ & $182(98.9)$ & $140(97.2)$ & \\
No & $6(1.8)$ & $2(1.1)$ & $4(2.8)$ & \\
\hline
\end{tabular}

Values are presented as number (\%). other cancers among females.

Conventionally, "elderly" has been defined as $\geq 65$ years old, and most developed countries have accepted the chronological age of 65 years as the definition of "elderly" or an older person [10]. Accordingly, the age group in our study was divided into the fol-

Table 3. Difference of locoregional recurrence or metastasis according to age

\begin{tabular}{lccc} 
Variable & $\begin{array}{c}\text { Overall } \\
(\mathrm{n}=328)\end{array}$ & $\begin{array}{c}\text { Age }<65 \text { years } \\
(\mathrm{n}=184)\end{array}$ & $\begin{array}{c}\text { Age } \geq 65 \text { years } \\
(\mathrm{n}=144)\end{array}$ \\
\hline Recurrence & $15(4.57)$ & $10(5.43)$ & $5(3.47)$ \\
Remnant breast & $6(1.83)$ & $6(3.26)$ & 0 \\
Axillary lymph & $7(2.14)$ & $2(1.09)$ & $5(3.47)$ \\
Chest wall & $1(0.30)$ & $1(0.54)$ & 0 \\
Multiple & $1(0.30)$ & $1(0.54)$ & 0 \\
Metastasis & $21(6.40)$ & $10(5.43)$ & $11(7.64)$ \\
Lung & $5(1.52)$ & $2(1.09)$ & $3(2.08)$ \\
Bones & $5(1.52)$ & $1(0.54)$ & $4(2.78)$ \\
Liver & $4(1.22)$ & $1(0.54)$ & $3(2.08)$ \\
Brain & $4(1.22)$ & $4(2.18)$ & 0 \\
Multiple & $3(0.91)$ & $2(1.09)$ & $1(0.70)$ \\
Death & $17(5.18)$ & $5(2.72)$ & $12(8.33)$ \\
\hline
\end{tabular}

Values are presented as number (\%).

Table 4. Univariate and multivariate Cox regression analyses for overall survival

\begin{tabular}{|c|c|c|c|c|}
\hline \multirow{2}{*}{ Factor } & \multicolumn{2}{|c|}{ Univariate analysis } & \multicolumn{2}{|c|}{ Multivariate analysis } \\
\hline & HR (95\% Cl) & P-value & HR $(95 \% \mathrm{Cl})$ & P-value \\
\hline \multicolumn{5}{|l|}{ pT } \\
\hline $\mathrm{T} 1$ & Reference & & Reference & \\
\hline $\mathrm{T} 2$ & $2.54(1.14-5.72)$ & 0.024 & $2.54(-1.13-5.71)$ & 0.024 \\
\hline $\mathrm{T} 3$ & $9.11(3.34-24.81)$ & $<0.001$ & $9.11(3.34-24.82)$ & $<0.001$ \\
\hline T4 & $10.04(2.68-37.54)$ & 0.001 & $10.04(2.68-37.54)$ & 0.001 \\
\hline \multicolumn{5}{|l|}{$\mathrm{pN}$} \\
\hline No & Reference & & & \\
\hline N1 & $2.24(1.04-4.84)$ & 0.040 & & \\
\hline N2 & $3.72(1.31-10.61)$ & 0.140 & & \\
\hline N3 & $5.66(1.96-16.14)$ & 0.001 & & \\
\hline \multicolumn{5}{|l|}{ TNM stage } \\
\hline 1 & Reference & & & \\
\hline 2 & $2.49(1.03-6.07)$ & 0.040 & & \\
\hline 3 & 6.89 (2.69-17.62) & $<0.001$ & & \\
\hline \multicolumn{5}{|c|}{ Nuclear grade } \\
\hline 1 & Reference & & & \\
\hline 2 & $2.19(0.88-5.49)$ & 0.090 & & \\
\hline 3 & $4.23(1.53-11.75)$ & 0.006 & & \\
\hline \multicolumn{5}{|l|}{ Ki-67 } \\
\hline$<15 \%$ & Reference & & & \\
\hline$\geq 15 \%$ & $2.28(1.18-4.41)$ & 0.014 & & \\
\hline
\end{tabular}

$\mathrm{HR}$, hazard ratio; $\mathrm{Cl}$, confidence interval. 
lowing two groups: $<65$ and $\geq 65$ years old.

In this study, BMI was relatively high among the elderly $(\mathrm{P}<$ 0.001 ) because as people get older, basal metabolic rate, physical activity, and social activity are decreased; post-menopausal women experience numerous metabolic changes due to changes in female hormones, and, especially at this time, women are at high risk for

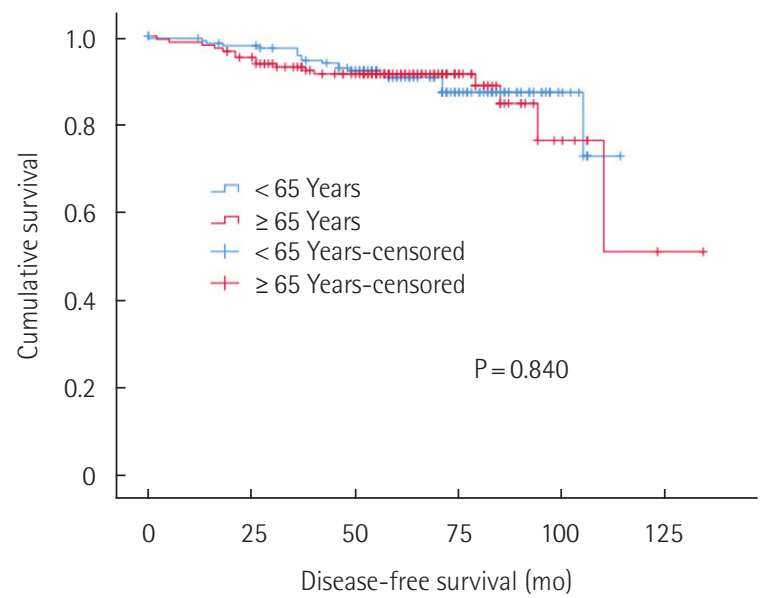

Fig. 1. Disease-free survival according to age groups. obesity due to increased body fat [11].

Moreover, obesity among these women is highly related to the development of lifestyle diseases, such as coronary artery and heart disease, stroke, diabetes, and hypertension, that increase mortality $[11,12]$.

Similar to that in other countries, South Korea provides breast

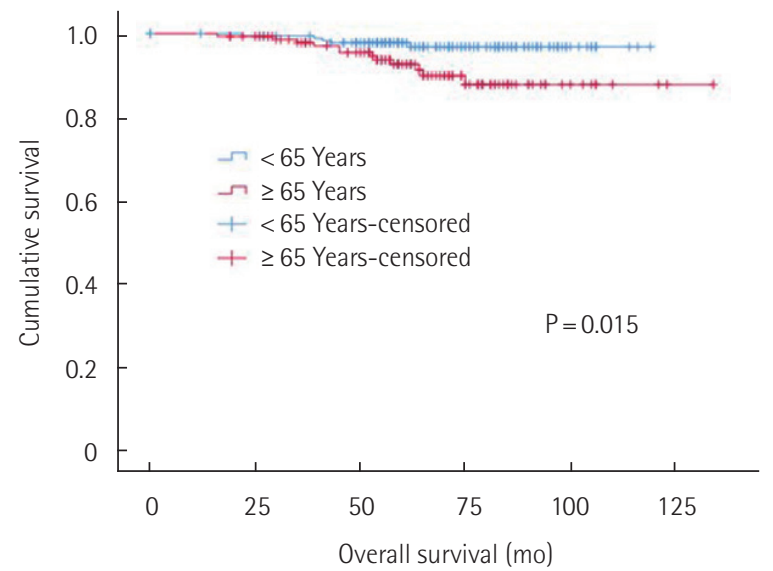

Fig. 2. Overall survival according to age groups.

Table 5. Univariate and multivariate Cox regression analyses for disease-free survival

\begin{tabular}{|c|c|c|c|c|}
\hline \multirow{2}{*}{ Factor } & \multicolumn{2}{|c|}{ Univariate analysis } & \multicolumn{2}{|c|}{ Multivariate analysis } \\
\hline & $\mathrm{HR}(95 \% \mathrm{Cl})$ & P-value & $\mathrm{HR}(95 \% \mathrm{Cl})$ & P-value \\
\hline Age (yr) & & & & 0.037 \\
\hline$<65$ & Reference & & Reference & \\
\hline$\geq 65$ & $3.37(1.19-9.59)$ & 0.015 & $3.71(1.08-12.79)$ & \\
\hline \multicolumn{5}{|l|}{ BMI $\left(\mathrm{kg} / \mathrm{m}^{2}\right)$} \\
\hline Underweight $(<18.5)$ & Reference & & & \\
\hline Normal weight (18.5 to <23) & $0.11(0.03-0.42)$ & 0.001 & & \\
\hline Overweight (23 to <25) & $0.04(0.01-0.22)$ & $<0.001$ & & \\
\hline Obesity (25 to <30) & $0.05(0.01-0.22)$ & $<0.001$ & & \\
\hline Severe obesity (>34) & $0.08(0.01-0.73)$ & 0.026 & & \\
\hline \multicolumn{5}{|l|}{ Type of surgery } \\
\hline Breast conservation & Reference & & & \\
\hline Mastectomy & $4.62(1.64-13.18)$ & 0.001 & & \\
\hline \multicolumn{5}{|l|}{ pT } \\
\hline $\mathrm{T} 1$ & Reference & & Reference & \\
\hline $\mathrm{T} 2$ & $4.11(1.11-15.15)$ & 0.034 & $3.34(0.83-13.46)$ & 0.090 \\
\hline T3 & $9.32(1.84-46.43)$ & 0.006 & $9.79(1.73-55.45)$ & 0.010 \\
\hline $\mathrm{T} 4$ & $16.51(2.75-99.13)$ & 0.002 & 23.65 (3.33-167.78) & 0.002 \\
\hline \multicolumn{5}{|l|}{ Hormone therapy } \\
\hline No & Reference & & Reference & \\
\hline Yes & $0.03(0.01-0.11)$ & $<0.001$ & $0.09(0.02-0.53)$ & 0.008 \\
\hline \multicolumn{5}{|l|}{ Ki-67 } \\
\hline$<15 \%$ & Reference & & Reference & \\
\hline$\geq 15 \%$ & $3.94(1.46-10.65)$ & 0.004 & $4.91(1.36-17.72)$ & 0.015 \\
\hline
\end{tabular}

$\mathrm{HR}$, hazard ratio; $\mathrm{Cl}$, confidence interval; $\mathrm{BMI}$, body mass index. 
cancer screening for women over the age of 40 years $[13,14]$. However, in the elderly population, examinations are not performed regularly, and high $\mathrm{T}$ stages are more commonly observed due to delayed diagnosis [15].

In our study, patients older than 65 years were more likely to be diagnosed with high $\mathrm{T}$ stage breast cancer than younger patients were $(\mathrm{P}=0.041)$; nevertheless, the difference in the overall stage was not significant. However, tumor stage is one of the risk factors for increased OS and DFS. Early detection is considered to be an important factor during breast cancer screening tests or self-examination.

Elderly women were more likely to undergo mastectomy (59.7\%) than younger women were $(18.5 \%)(\mathrm{P}<0.001)$, and there was a tendency to omit postoperative radiation therapy. This difference in surgical methods can be attributed not only to the elderly being less sensitive to their body image or to cosmetic results but also to the high $\mathrm{T}$ stage at the time of diagnosis.

As reported in previous studies, receiving chemotherapy is closely related to the cancer stage and HR status [16,17]. Elderly patients less frequently receive systemic therapy, particularly chemotherapy. The reasons for this difference in treatment may be due to the higher rate of comorbidities, the patient's or family preferences, concerns about quality of life, and low life expectancy.

Hormonal therapy has been reported to be independent of age [15]. This is because it is easier for patients to adjust to the drug in the short term, but long-term compliance tends to decline; therefore, long-term outcomes require follow-up.

HR+ HER2- breast cancer is not aggressive [18], and elderly patients can be treated with hormones and have good compliance.

In this study, there was no difference in DFS between the two age groups; however, the OS in the older age group was significantly lower than that in the younger age group. The reasons for the decrease in OS in older patients include the high stage at the time of diagnosis, short life expectancy, high comorbidity rate, and lack of active treatment. In our study, both all-cause mortality and breast cancer-specific mortality were higher in the older age group. It was thought that comorbidity would affect both mortality rates. The proportion of lifestyle diseases such as hypertension and diabetes were significantly higher in the older (Table 1) and one of the older age group died from atrial fibrillation. Cancer incidence rate increases with age, and in this study, the incidence rate of other organ cancers was higher in the older age group than in the younger group.

The difference in overall stage between age groups was not significant, but a high $\mathrm{T}$ stage in old age is generally considered to affect the overall stage and prognosis. These factors are thought to be directly or indirectly responsible for the reduction of OS in old age as they reduce compliance with postoperative recovery, chemotherapy, radiation therapy, and endocrine therapy.

Previously, many studies on similar subjects have already been reported, and this study has the limitation of being a retrospective study of a single institution. Also, accurate comparison through propensity score matching between the two groups is necessary, but the analysis is likely to be difficult due to the small number of target groups.

In conclusion, this study suggested that HR+ HER2- breast cancer patients belonging to the two age groups had no significant difference in DFS. However, older age is an independent factor affecting the OS rate. Therefore, even if patients are old, standard and active treatment may be necessary, similar to that in younger patients, for the older patients with satisfactory physical condition. For such active treatment to be achieved, early detection through continuous regular check-ups is necessary, even among the elderly.

\section{CONFLICT OF INTEREST}

No potential conflict of interest relevant to this article was reported.

\section{REFERENCES}

1. Statistics Korea. 2015 Statistical report on the aged [Internet]. Daejeon (KR): Korea Statistical Information System; c2015 [cited 2020 Jun 1]. Available from: https://kosis.kr/statisticsList/statisticsListIndex. do?publicationYN=Y\&statId=1997018\#content-group.

2. Jemal A, Ward E, Thun MJ. Recent trends in breast cancer incidence rates by age and tumor characteristics among U.S. women. Breast Cancer Res 2007;9:R28.

3. Goodwin JS, Hunt WC, Humble CG, Key CR, Samet JM. Cancer treatment protocols: who gets chosen? Arch Intern Med 1988;148: 2258-60.

4. Westphal T, Rinnerthaler G, Mlineritsch B. Adjuvant medical treatment for breast cancer in elderly and old women. Memo 2016; 9:17-9.

5. Rocco N, Rispoli C, Pagano G, Ascione S, Compagna R, Danzi M, et al. Undertreatment of breast cancer in the elderly. BMC Surg 2013;13 (Suppl 2):S26.

6. Fisher CJ, Egan MK, Smith P, Wicks K, Millis RR, Fentiman IS. Histopathology of breast cancer in relation to age. Br J Cancer 1997; 75:593-6.

7. Lee SK, Kim SW, Yu JH, Lee JE, Kim JY, Woo J, et al. Is the high proportion of young age at breast cancer onset a unique feature of Asian breast cancer? Breast Cancer Res Treat 2019;173:189-99.

8. Tew WP, Muss HB, Kimmick GG, Von Gruenigen VE, Lichtman SM. Breast and ovarian cancer in the older woman. J Clin Oncol 
2014;32:2553-61.

9. Diab SG, Elledge RM, Clark GM. Tumor characteristics and clinical outcome of elderly women with breast cancer. J Natl Cancer Inst 2000;92:550-6.

10. Orimo H. Reviewing the definition of elderly. Nihon Ronen Igakkai Zasshi 2006;43:27-34.

11. Eckel RH. Obesity: mechanisms and clinical management. Philadelphia, PA: Lippincott Williams \& Wilkins; 2003.

12. Bang S, Cho I. The effects of menopause on the metabolic syndrome in Korean women. J Korea Acad Ind Coop Soc 2015;16: 2704-12.

13. Fletcher SW, Elmore JG. Mammographic screening for breast cancer. N Engl J Med 2003;348:1672-80.

14. Bevers TB, Helvie M, Bonaccio E, Calhoun KE, Daly MB, Farrar WB, et al. Breast cancer screening and diagnosis, version 3.2018, NCCN clinical practice guidelines in oncology. J Natl Compr Canc
Netw 2018;16:1362-89.

15. Gennari R, Curigliano G, Rotmensz N, Robertson C, Colleoni M, Zurrida S, et al. Breast carcinoma in elderly women: features of disease presentation, choice of local and systemic treatments compared with younger postmenopasual patients. Cancer 2004;101: 1302-10.

16. Giordano SH, Hortobagyi GN, Kau SW, Theriault RL, Bondy ML. Breast cancer treatment guidelines in older women. J Clin Oncol 2005;23:783-91.

17. Mandelblatt JS, Sheppard VB, Hurria A, Kimmick G, Isaacs C, Taylor KL, et al. Breast cancer adjuvant chemotherapy decisions in older women: the role of patient preference and interactions with physicians. J Clin Oncol 2010;28:3146-53.

18. Fallahpour S, Navaneelan T, De P, Borgo A. Breast cancer survival by molecular subtype: a population-based analysis of cancer registry data. CMAJ Open 2017;5:E734-9. 